Publicação organizada pelo Programa de

Mestrado Profissional Stricto Sensu em

Engenharia Civil da Universidade São Judas

Volume 03 - Edição 01

Janeiro - Dezembro de 2020

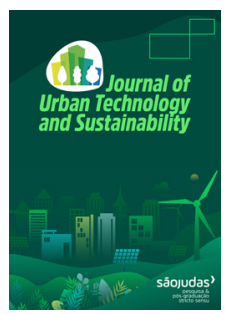

\title{
A seca e seus desdobramentos: reflexões a partir da realidade da Microrregião de Pau dos Ferros
}

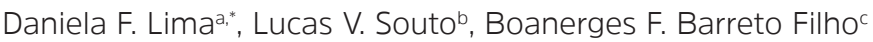

${ }^{a}$ Programa de pós-graduação em Engenharia Civil e Ambiental, Universidade Federal de Campina Grande, Campina Grande, Brasil.

${ }^{b}$ Programa de pós-graduação em Planejamento e Dinâmicas Territoriais do Semiárido, Universidade do Estado do Rio Grande do Norte, Mossoró, Brasil.

cDepartamento de Economia, Campus Avançado de Pau dos Ferros, Universidade do Estado do Rio Grande do Norte, Pau dos Ferros, Brasil.

\section{Informações}

Recebido 19 Setembro 2020

Manuscrito revisado recebido

19 Novembro 2020

Aceito 27 Novembro 2020

Palavras-chave

Dificuldade hídrica

Combate à seca

Convivência com a seca

Medidas emergenciais

\section{Resumo}

A região Nordeste sempre foi vista como a região da seca, do subdesenvolvimento, do homem desamparado e de diversos estereótipos que consagraram a caracterização de sua configuração humana, econômica e espacial. A ausência de água é um aspecto marcante, que além de flagelar o nordestino, é utilizada como aporte político por representantes governamentais em discursos de "solução à seca" para adquirirem apoio popular. O objetivo deste trabalho é apresentar a perda de importância das atividades rurais na microrregião de Pau dos Ferros/RN e discutir as medidas emergenciais adotadas para amenizar a escassez de água neste município. Foi realizado levantamento de dados com foco nas variáveis População e Produto Interno Bruto Agropecuário; coletados dados na Secretaria de Desenvolvimento Rural de Pau dos Ferros/RN; e realizadas buscas acerca da questão hídrica deste município em portais online. Diante disso, foi observada a relativa perda de participação do PIB agropecuário na composição do PIB Municipal, redução da população rural nessa microrregião e a implantação de ações paliativas de combate à seca.

\section{Drought and its consequences: reflections from the reality of the Pau dos Ferros Microregion}

\author{
Article info \\ Received 19 September \\ 2020 \\ Received in revised form 19 \\ November 2020 \\ Accepted 27 November \\ 2020 \\ Keywords \\ Water scarcity \\ Combat to drought \\ Living with drought \\ Emergency measures
}

\begin{abstract}
The Northeast region has always been the region of drought, underdevelopment, the destituous man and several other stereotypes that enshrined the characterization of their human, economic and spatial configuration. The absence of water is a striking aspect, which in addition to flagellating the Northeastern region, is used by government representatives to adopt "solution to drought" speeches to acquire popular support. The objective of this work is to present the loss of importance of rural activities in the microregion of Pau dos Ferros/RN and to discuss the emergency measures adopted to alleviate water scarcity with emphasis in this municipality. Data were collected focusing on the variables Population and Gross Agricultural Domestic Product; data were collected at the Secretariat of Rural Development of Pau dos Ferros/RN city; and searches were carried out about the water issue of this municipality in online portals. Therefore, what was observed was the relative loss of participation of agricultural GDP in the composition of municipal GDP, reduction of the rural population in this microregion and the implementation of palliative actions to combat drought.
\end{abstract}

\section{La sequía y sus consecuencias: reflexiones desde la realidad de la Microrregión de Pau dos Ferros}

\section{Información}

Recibido 19 Septiembre 2020

Manuscrito revisado recibido 19 Noviembre 2020

Aceptado 27 Noviembre 2020

\section{Palabras clave}

Falta de agua

Combate a la sequía

Convivir con la sequía

Medidas emergenciales

\section{Resumen}

La región Nordeste siempre ha sido vista como la región de la sequía, el subdesarrollo, el hombre indefenso y diversos estereotipos que consagraron la caracterización de su configuración humana, económica y espacial. La ausencia de agua es un aspecto llamativo que, además de azotar al Nordeste, es utilizado como aporte político por los representantes del gobierno en discursos de "solución a la sequía" para ganar apoyo popular. El objetivo de este trabajo es presentar la pérdida de importancia de las actividades rurales en la micro región de Pau dos Ferros / RN y discutir las medidas de emergencia adoptadas para paliar la escasez de agua en este municipio. Se realizó una encuesta de datos con foco en las variables Población y Producto Interno Bruto Agropecuario; los datos se recopilaron en la Secretaría de Desarrollo Rural de Pau dos Ferros / RN; y se realizaron búsquedas sobre el tema del agua de este municipio en portales en línea. Ante esto, se observó la pérdida relativa de participación del PIB agrícola en la composición del PIB Municipal, la reducción de la población rural en esta microrregión y la implementación de acciones paliativas para combatir la sequía.

\footnotetext{
* Autor correspondente em: Departamento de Engenharia Civil e Ambiental, Universidade Federal de Campina Grande, Campina Grande, Brasil. 


\section{Introdução}

A seca é uma das características mais ressaltadas quando se faz referência ao Nordeste, seguida pelo discurso que a descreve como a região da pobreza, da miséria, do subdesenvolvimento e dos flagelados. Assim, a partir de uma característica climática, constrói-se uma narrativa, ou melhor, uma imagem sobre uma imensa área geográfica marcada por estereótipos e por preconceito.

Essa trama foi sendo construída e consolidada através dos grandes jornais do Sudeste, de São Paulo e do Rio de Janeiro principalmente, a partir da cobertura de fatos históricos, como a Guerra de Canudos, o Cangaço, as sucessivas secas, contribuiu também a literatura regionalista ${ }^{1}$ e ainda, talvez o componente mais emblemático, o discurso da elite política nordestina. O poder dessa construção imagética se cristaliza pelo apoio das massas e se propaga, por várias décadas, fazendo com que parte dos nordestinos se considere na condição de subalternidade e castigado pela inclemência da natureza.

Saliente-se que as intervenções pontuais realizadas pelas autoridades públicas, através da construção de alguns reservatórios e dos socorros públicos nos períodos de secas mais severas, só ganham contornos de políticas públicas a partir da criação de órgãos especializados para o enfrentamento do problema, dentre eles: Comissão Imperial; Inspetoria Federal de Obras Contra às Secas (IFOCS), Departamento Nacional de Obras Contra às Secas (DNOCS), Superintendência de Desenvolvimento do Nordeste (SUDENE) ${ }^{2}$.

\footnotetext{
1 De acordo com Albuquerque Júnior (2017, p. 225): "essa literatura construiu um conjunto de imagens e enunciados que, ainda hoje, permanecem como o 'ser' mesmo da seca do Nordeste do Brasil. Ignoradas pela vasta produção historiográfica existente a respeito desse fenômeno, essas imagens e cenas vão ser figuradas, inicialmente, e recorrentemente reapresentadas na produção literária que se diz regionalista, sendo posteriormente apropriadas por outros gêneros narrativos e artísticos. Mesmo em permanente reelaboração e reinscrição, essas imagens retirantes, sobrevivem e retornam periodicamente nos discursos em torno desse fenômeno dito regional".
}

2 A SUDENE não é um órgão público especializado no combate à seca, mas se insere na lógica do paradigma da modernidade e do discurso da elite política regional. Embora seja necessário ressaltar a diferenciação entre o propósito originário para sua criação, demonstrado no trabalho chefiado por Celso Furtado e que resultou no Relatório do Grupo de Trabalho para o Desenvolvimento do Nordeste (GTDN), em comparação com as
Neste aspecto, a preponderância deste enredo discursivo se encontra com o paradigma da modernidade, uma vez que a realização de grandes obras de infraestrutura hídrica é a forma de manifestação concreta, ensejando, portanto, a perspectiva tecnicista da primazia humana sobre a natureza e de sua utilização para fins de exploração econômica (SILVA, 2003). Podese afirmar que o paradigma do combate à seca foi o balizador das intervenções realizadas pelo Estado brasileiro ao longo do tempo no Semiárido, direcionando-se volumes expressivos de recursos para obras de construção de grandes reservatórios hídricos e ações subsidiárias, como a implantação de perímetros irrigados, a construção de sistemas adutores e, mais recentemente, inaugurandose uma nova forma de intervenção, a partir da transposição de águas do rio São Francisco.

Contudo, mesmo considerando a relevância das intervenções, evidencia-se que as realidades socioeconômica e ambiental predominantes no Semiárido ainda são marcadas por elevados índices de pobreza, baixíssimo dinamismo econômico e acentuado processo de degradação da natureza. Sendo plausível supor que a situação não é ainda mais dramática em função do intenso processo de migração, do rural para o urbano, em que milhares de pessoas acorreram para as cidades em busca de melhorias nas condições de vida, acrescido de ações implementadas pelo Estado, preponderantemente orientadas pelo paradigma do combate à seca e por um número menor de experiências relacionadas à convivência.

Ao longo do tempo a migração campo-cidade ocorreu de forma acentuada na Microrregião de Pau dos Ferros, fortemente influenciada pelas consequências da seca, fenômeno natural recorrente que, historicamente, não recebeu a devida atenção por parte das autoridades públicas. O que ocorreu desde a transição dos séculos XIX para o XX até os dias atuais foram os gastos excessivos com o combate à seca (SILVA, 2007),

ações realizadas, especialmente após o golpe militar de 1964, notadamente, subordinadas à estratégia de industrialização, espacialmente concentrada no Centro Sul e cabendo ao setor industrial nordestino o papel de complementação, bem como a estratégia de desenvolvimento rural fundamentada na modernização conservadora da agricultura. 
por meio de vultuosos investimentos na construção de barragens, adutoras, distribuição de água e políticas de transferência de renda. Reconhecese que essas medidas de combate são, em curto prazo, importantes para a população, mas não possibilitam uma convivência que promova a fixação do homem na zona rural e nem foram capazes de proporcionar desenvolvimento humano, ou seja, aumento do bem-estar.

$\mathrm{Na}$ Microrregião de Pau dos Ferros ocorreu um intenso processo de migração, do rural para o urbano, onde as pessoas deslocavam-se em busca de melhoria de vida. Dantas e França (2016) apontam que, "ocorreram mudanças econômicas, sociais, demográficas e espaciais em todo o país, mas essas mudanças não foram capazes de modificar, em termos estruturais, as disparidades regionais existentes". Consequentemente graves problemas sociais relacionados à moradia, saúde, educação, emprego e renda se tornaram mais evidenciados nas áreas mais pobres do país, como é o caso da área objeto deste estudo.

O município que dá nome a Microrregião, Pau dos Ferros/RN, exerce uma grande influência sobre os demais municípios circunvizinhos por seu potencial na oferta de serviços e empregos, podendo ser caracterizada como cidade (inter)média devido ao atributo de intermediação e polarização entre diversas cidades, como apontaram Dantas, Clementino e França (2014).

Os mecanismos de expulsão/atração são complexos, mas é defensável que a extrema pobreza rural existente no Nordeste seja um incentivo para a migração. Acrescentem-se a ausência/ insuficiência de medidas mitigadoras do problema e os incentivos, velados e explícitos, por parte do Estado brasileiro para acelerar a urbanização que se compreende a transumância nos períodos de secas mais duradoras.

Acredita-se que a extrema pobreza e pobreza do meio rural do Semiárido, em geral, e da Microrregião de Pau dos Ferros, em particular, em associação com o fenômeno da seca e de ausência/insuficiência de medidas mitigadoras foram determinantes para a migração campo-cidade que ocorreu de forma acentuada na Microrregião de Pau dos Ferros.
Neste sentido, o trabalho objetiva apresentar a perda de importância das atividades rurais na Microrregião de Pau dos Ferros e debater acerca das medidas emergenciais utilizadas para reduzir a dificuldade de acesso à água no semiárido nordestino, decorrente da irregularidade dos períodos chuvosos, com ênfase no município de Pau dos Ferros/RN por ser bastante representativo da realidade microrregional.

Alguns elementos, como a demografia, especialmente a evolução da população rural; a economia, com ênfase na participação do Setor Agropecuário na composição do Produto Interno Bruto (PIB) municipal; e as ações do Estado relacionadas à seca, oferecem subsídios para respaldar a discussão.

\section{Metodologia}

\section{1. Área de estudo}

Segundo a classificação das cidades dada pelo IBGE, todas as cidades que compõem esse estudo enquadram-se como cidades de pequeno porte, pois possuem população abaixo de 100 mil habitantes. Mas, Pau dos Ferros/RN contraria essa lógica, caracterizando-se como uma cidade (inter) média, devido a sua forte capacidade polarizadora e de influência na região, onde são ofertados serviços variados (educação, saúde, jurídicos, bancários e etc.), sendo um centro comercial regional onde se tem grande volume de negócios, que impactam no emprego e na renda (DANTAS, 2014).

A respeito do processo de constituição de Pau dos Ferros/RN e dos municípios que o circundam, Dantas, Clementino e França (2014), relatam que, o processo de formação teve origem no capital mercantil através do binômio gado-algodão que movimentou a economia do sertão nordestino por muito tempo.

Essa microrregião é localizada na área do semiárido brasileiro, mais especificamente no Alto Oeste do estado do Rio Grande do Norte. O bioma preponderante é a Caatinga, vegetação essa específica das áreas de clima seco que conseguem 


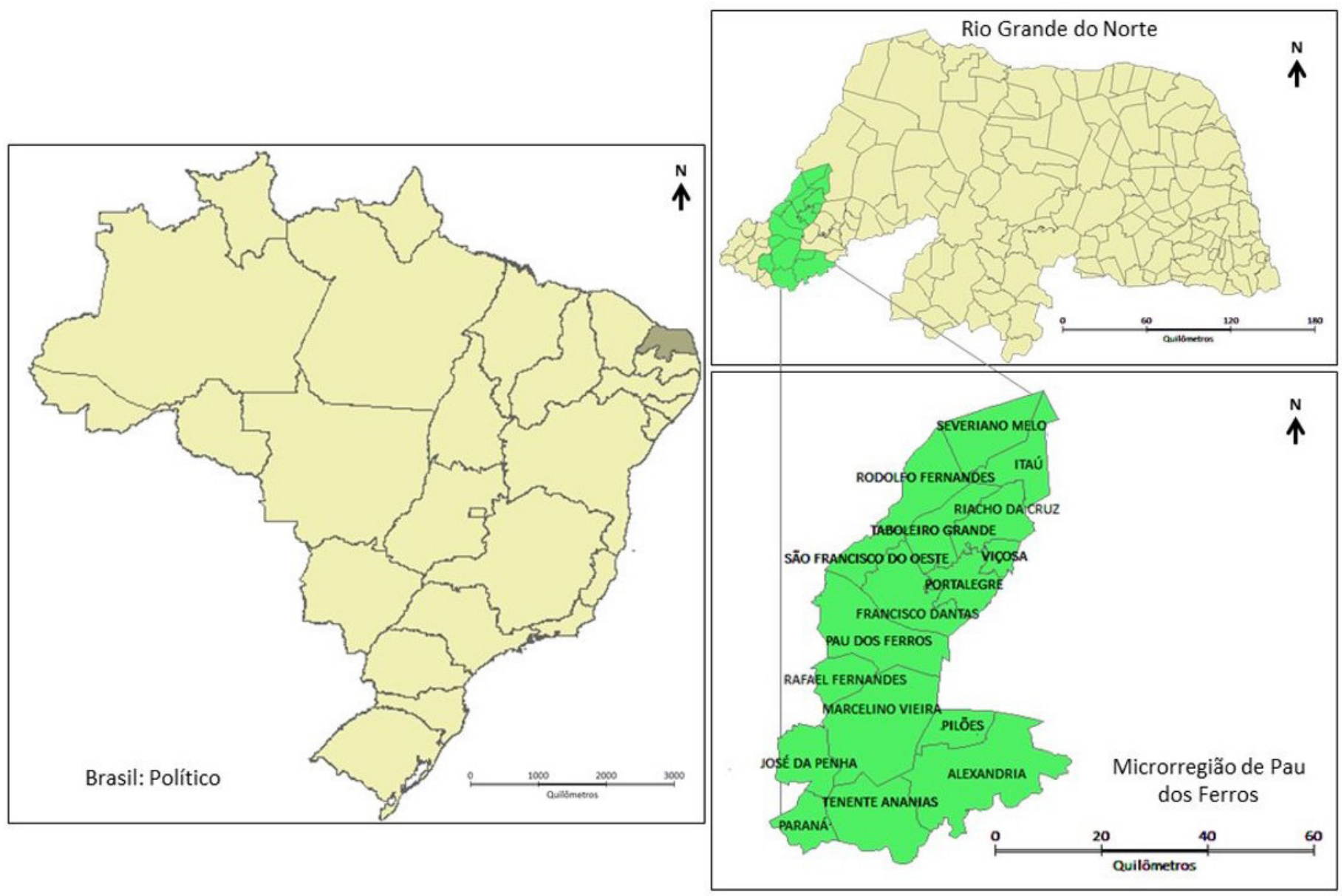

Fig. 1. Municípios que compõem a Microrregião de Pau dos Ferros (SOUTO; SOUSA JUNIOR; LIMA JÚNIOR, 2019).

suportar grandes períodos de estiagem. A média pluviométrica varia de 200 a 800 mm ano (AB'SABER, 2003).

A Figura 1 mostra a localização geográfica e externa os dezessete municípios que compõem a microrregião, onde a maioria destes possuem baixa densidade populacional. Em 2010, os 17 municípios tinham uma população de 114.267 habitantes, alcançando, em 2019, uma população estimada de 117.812 habitantes (IBGE, 2010; 2020).

Em 2010, 15 municípios tinham menos de 10 mil habitantes, destacando-se Pau dos Ferros/ RN com 27.745 habitantes (maior população) e o município de Viçosa/RN com 1.618 habitantes (menor população) (IBGE, 2010). Em 2020, Pau dos Ferros/RN, com 30.600 habitantes, continua como o município de maior população e Viçosa/ RN, com 1.725 habitantes, o de menor população (IBGE, 2020).

De acordo com o Atlas do Desenvolvimento Humano no Brasil (2010), o Índice de Desenvolvimento Humano Municipal (IDHM) médio da microrregião é de 0,6099, isso caracteriza os municípios de acordo com a metodologia do índice na categoria de médio desenvolvimento. A variável que mais contribuiu para a melhoria do desenvolvimento humano nesses municípios foi a variável "Longevidade". Quando se fala de concentração de renda, o Índice de Gini médio auferido é de aproximadamente 0,4847.

\subsection{Procedimentos metodológicos}

Para consecução do presente trabalho foram adotadas as fases:

- Realização de um estudo de levantamento dos dados disponibilizados nas bases do Instituto Brasileiro de Geografia e Estatística (IBGE). As variáveis selecionadas para análise dos municípios que compõem a microrregião de Pau dos Ferros/ RN foram População e Produto Interno Bruto Agropecuário;

- Execução de coleta de documental no ano de 2016, composta por relatórios da perfuração de 
poços em Pau dos Ferros/RN na Secretaria de Desenvolvimento Rural do município de Pau dos Ferros/RN;

- Visitas in loco no ano de 2016 para verificação da situação hídrica e medidas adotadas para atenuar os impactos negativos da escassez em Pau dos Ferros/RN;

- Investigação do panorama hídrico de Pau dos Ferros/RN em portais online dos órgãos associados à gestão de água do Rio Grande do Norte e da Agência Nacional de Águas (ANA).

\section{O fator climático e suas implicações na dinâmica regional}

De acordo com a Resolução $n^{0} 115$, de 23/11/2017, do Ministério da Integração Nacional e Superintendência do Desenvolvimento do Nordeste (SUDENE), o Semiárido brasileiro é composto por 1.262 municípios, dos estados do Maranhão, Piauí, Ceará, Rio Grande do Norte, Paraíba, Pernambuco, Alagoas, Sergipe, Bahia e Minas Gerais. A Figura 2 apresenta o recorte geográfico indicado nesta Resolução (SUDENE, 2017).

Dados da SUDENE (2017) expõem que 22,5\% dos municípios do Brasil são integrantes do Semiárido, dos quais o Nordeste abriga a liderança deste quantitativo, 1171 dos 1262 municípios, e o Rio Grande do Norte detém 147 (dos 167 inseridos em seu território).

Apesar do semiárido nordestino ser uma das regiões que possuem o clima semiárido com maior capacidade de armazenamento de água do mundo, seus reservatórios são a céu aberto, além de não haver manutenção periódica para desassoreamento e recuperação de matas ciliares, o que facilita a evapotranspiração que, de acordo com Malvezzi (2007) é três vezes maior do que os índices de precipitação. Além da evapotranspiração, que ocorre com maior intensidade quanto mais raso for o reservatório, $70 \%$ do solo do semiárido é cristalino, o que dificulta a infiltração, fazendo com que água das chuvas escoe para os rios intermitentes e, posteriormente deságue no mar ou evapore antes deste fenômeno.

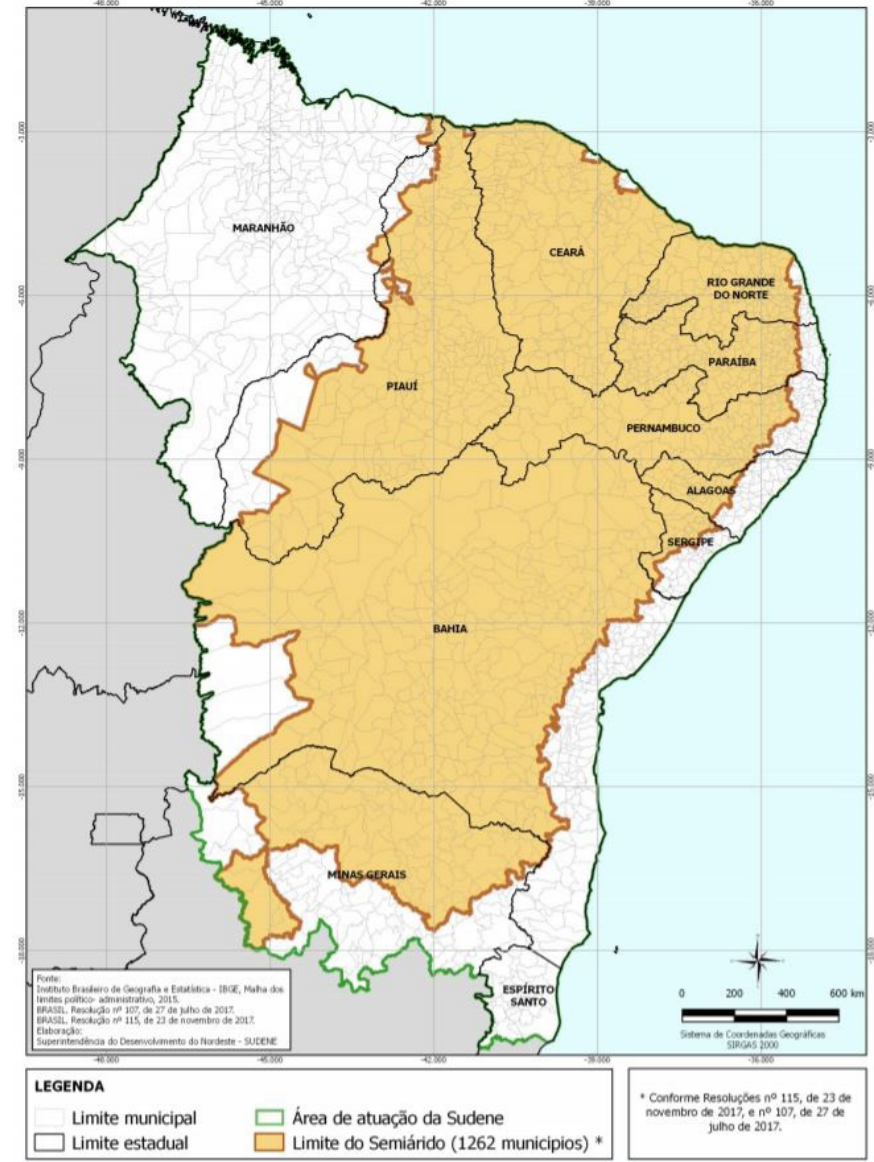

Fig. 2. Espaço geográfico no semiárido (SUDENE, 2017).

O semiárido nordestino é o mais chuvoso do planeta, com pluviosidade média de 750 mm/ ano. Assim, a convivência com o semiárido não corresponde a extinguir a seca, mas adaptar-se ao ambiente de forma inteligente, que corresponde principalmente ao armazenamento de água com o impedimento da evaporação. A exemplo de técnicas de captação e armazenamento estão as cisternas de placas, que são hermeticamente fechadas e captam água das chuvas por meio de calhas (MALVEZZI, 2007).

Foi a partir dos anos 1980 que a sociedade civil e entidades públicas de pesquisa passaram a implantar mecanismos de convivência com o semiárido, rompendo com o antigo paradigma do combate que beneficiou a indústria da seca durante todo o século XX (SILVA, 2007).

Uma dessas entidades que disseminam técnicas de convivência com o semiárido é a Articulação no Semiárido Brasileiro (ASA), formada pela união de diversas organizações da sociedade civil, constituída no início da década de 1990, que possui em seu escopo vários programas que viabilizam a 
permanência e a subsistência da população que vive na região semiárida brasileira. Entre seus programas estão: Programa Um Milhão de Cisternas (P1MC), Programa Uma Terra e Duas Águas (P1+2), Programa Cisternas nas Escolas, Programa de Manejo da Agrobiodiversidade (Sementes do Semiárido).

O P1MC que é o carro chefe e tem como objetivo construir cisternas de placa nas casas das zonas rurais para que seja armazenada a água da chuva no inverno para quando o período de estiagem chegar essa população possa ter pelo menos água para o consumo humano. Até novembro de 2016, ano foco deste trabalho, foram construídas 588.935 cisternas em toda região semiárida, o que representa 59\% do objetivo final (ASA, 2016). Esse número evoluiu para 628.355 até setembro de 2020 (ASA, 2020). A ASA recebe recursos do governo federal e de entidades privadas para que possa continuar o trabalho junto a população alvo.

Como já é sabido e amplamente divulgado, a região semiárida nordestina apresenta grandes períodos de estiagem desde o início de seus registros, que datam da época do Brasil colônia. Neste aspecto, a Microrregião de Pau dos Ferros foi e continua sendo muito afetada pela ocorrência de secas. A mais recente ocorreu no período de 2012 a 2017, resultando em diversos problemas ambientais, sociais e econômicos. Ressalta-se que os anos de 2011, 2018 e 2019 também não tiveram pluviometria favorável em Pau dos Ferros/RN e o reservatório principal desta cidade não obteve recarga satisfatória para atendimento de suas demandas.

Muito embora a Microrregião de Pau dos Ferros tenha o Setor de Serviços como principal fator dinamizador da economia, observa-se que ainda existe uma presença marcante da agricultura familiar, nem tanto no sentido estritamente econômico, mas como elemento representativo da história, da cultura e da conformação social microrregional.

Salienta-se que o Setor Agropecuário microrregional é caracterizado pela ausência de mecanização ou técnicas sofisticadas que auxiliam na produção, impactando na baixa produtividade e baixa escala das culturas. Para que se tenha aumento de produtividade são necessárias políticas públicas e aporte de recursos públicos e privados.

Todavia, o capital tende a se mover para os territórios e setores onde pode auferir maior retorno, consequentemente, caso não ocorra a intervenção do poder público nas áreas predominantemente semiáridas, o capital privado não será direcionado para tais áreas, mantendo-as em desvantagens, subdesenvolvida e obsoleta frente às áreas de expansão do agronegócio das regiões Sul, CentroOeste e Sudeste do país.

Ou seja, é de extrema importância a efetivação de políticas públicas que fomentem o desenvolvimento da região semiárida, que colabore para que a população que vive nesse espaço possa permanecer nele e dele retirar renda suficiente para prover níveis satisfatórios de bem-estar.

Existem diversos exemplos internos e externos de que a convivência com as regiões áridas e semiáridas é totalmente possível e viável. A nível externo ao país, tem-se o caso de Israel, país localizados no oriente médio, mais especificamente no continente asiático, onde este possui vasta região de clima árido, baixa incidência pluviométrica, escassez de água e boa parte dos solos desérticos, mas que sempre buscou mecanismos para conviver com as intempéries do clima, tanto que se apresentam como os pioneiros nas técnicas de irrigação por gotejamento, dessalinização da água e reaproveitamento da água do esgoto para irrigação, sendo hoje autossuficientes em diversas culturas (BLECHER, 2012).

Do ponto de vista interno, há ilhas de prosperidade que estão na região semiárida, como são os casos da região de Juazeiro/Petrolina (Bahia/Pernambuco), as margens do rio São Francisco, de Açu/Mossoró (RN) e Morada Nova/Limoeiro do Norte (CE), áreas estas que estão sob a égide da indústria agrícola tipo exportação, mas que apresentam alta produtividade e grande escala, pois têm acesso aos principais insumos: água, terra e capital humano.

A Figura 3 mostra os níveis da seca no Nordeste brasileiro, segundo a metodologia do Monitor de Secas, no mês de setembro do ano de 2016, ano 


\section{Setembro/2016}

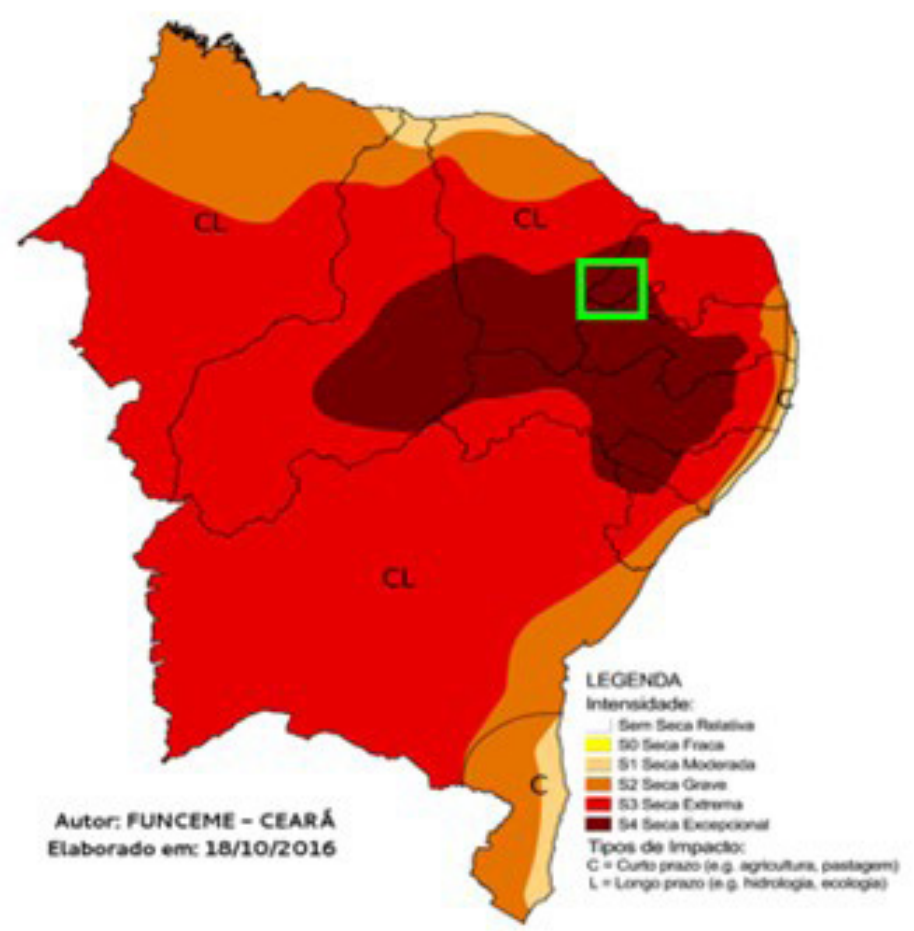

Julho/2020

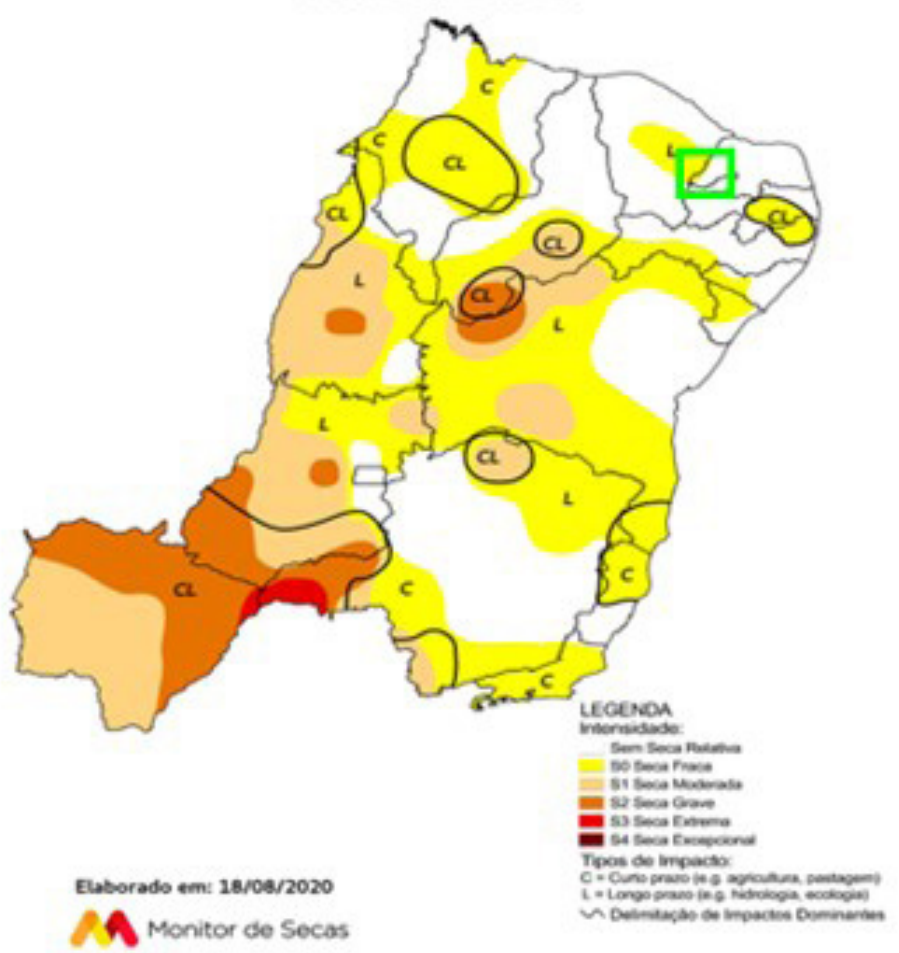

Fig. 3. Monitor de Secas (adaptado de ANA, 2020b).

base desta pesquisa, e no mês de julho de 2020, época em que a situação de escassez hídrica foi atenuada na microrregião objeto de estudo deste trabalho.

De acordo com a ANA (2020), o Monitor de Secas é um instrumento de análise regular e periódica da situação da seca no Nordeste, cujos resultados consolidados são divulgados por meio do Mapa do Monitor de Secas. Mensalmente informações sobre a situação de secas são disponibilizadas até o mês anterior, com indicadores que refletem o curto prazo (últimos 3, 4 e 6 meses) e o longo prazo (últimos 12, 18 e 24 meses), indicando a evolução da seca na região.

O monitor é composto por cinco categorias, com o intervalo que compreende SO a S4, onde SO é o nível mais fraco de seca e S4 é o nível mais forte, chamado seca excepcional. Na Figura 3, que exibe o referido monitor, a região analisada no presente trabalho está sinalizada dentro do quadrado verde, na parte oeste do estado do Rio Grande do Norte. Esta região era caracterizada no ano de 2016 pela categoria S4 (seca excepcional), onde os impactos da seca estavam em seu grau máximo, ocasionando: perdas de cultura; escassez de água nos reservatórios, córregos e poços de água; criando situações de emergência e calamidade pública, fato que motivou este estudo nesta época.

\section{Indicadores demográfico e econômico}

A partir da Figura 4 verifica-se que todos os municípios da Microrregião de Pau dos Ferros apresentaram redução da participação do PIB agropecuário sobre o PIB total municipal, tendo como ponto de referência o início da série e o final. Entre o ano de 2008 e 2012 a tendência de queda é observada de forma acentuada em todos os municípios em questão, após esse período o percentual de participação oscila em baixa.

Os dados apontam a perda de participação do Setor Agropecuário na economia dos municípios da Microrregião de Pau dos Ferros, demonstrando que as economias municipais se tornaram cada vez mais dependentes dos segmentos atrelados ao urbano, especialmente o Setor de Serviços. Os anos de 2016 e 2017 apresentaram os menores valores de representatividade para cerca de 65\% dos municípios da Microrregião de Pau dos Ferros, época de elevada escassez hídrica. 


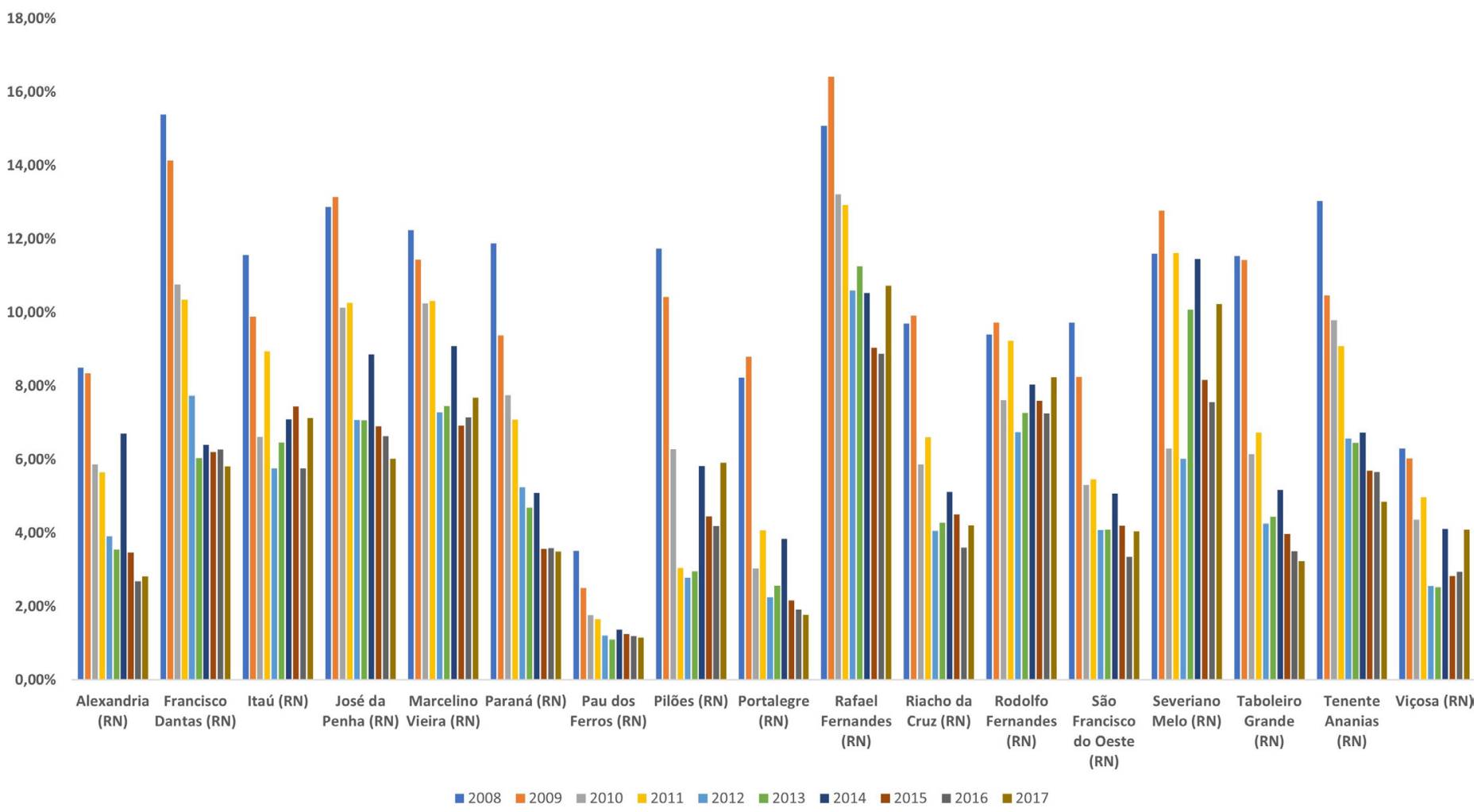

Fig. 4. Participação do PIB Agropecuário no PIB Total Municipal (\%) de 2008-2017 (adaptado de IBGE, 2019).

Apesar de algumas oscilações nos anos de 2003 a 2008, início da série do Instituto Brasileiro de Geografia e Estatística que contabiliza os produtos municipais, observa-se que o comportamento do PIB Agropecuário é de redução com o passar do tempo, sugerindo que a perda de importância do Setor Agropecuário já era uma tendência no espaço microrregional. Destaca-se que as políticas públicas implementadas no início do século XX não se destinaram a potenciar a pequena produção agropecuária. Ademais, pode-se presumir que - Programa Nacional de Fortalecimento da Agricultura Familiar (PRONAF, 1996), estabelecido Decreto n 1.946/1996, e o Programa de Aquisição de Alimento (PAA, 2003), instituído pela Lei $n^{\circ}$ 10.696/2003, não impactaram significativamente a agropecuária microrregional, mesmo num período de chuvas mais regulares, embora contribuindo, muito provavelmente, para aliviar a pobreza rural.

Observa-se, por meio da Figura 5, que ocorreu a diminuição da população rural na Microrregião de Pau dos Ferros/RN, no período que compreende os três últimos Censos Demográficos.

A tendência de redução da população rural é um fenômeno nacional que vem sendo a tônica do pós-Segunda Guerra Mundial, mas com diferentes velocidades nos distintos recortes geográficos, em geral, obedecendo ao sentido de deslocamento populacional de áreas pobres para aquelas com maior dinamismo econômico. Verifica-se que, no período de 1991 para 2010, a população rural diminuiu oito pontos percentuais no Brasil, nove pontos percentuais no Rio Grande do Norte e dezesseis pontos percentuais na Microrregião de Pau dos Ferros, restando evidente que o estado potiguar vem acompanhando o ritmo nacional e a Microrregião apresenta um ritmo mais intenso de queda da população rural.

\section{Panorama hídrico de Pau dos Ferros}

No ano de 2016, o principal reservatório do município de Pau dos Ferros/RN, denominado Barragem de Pau dos Ferros, estava com sua capacidade de abastecimento totalmente esgotada em decorrência das escassas precipitações na região que o abasteciam, consequência da forte seca apresentada desde anos anteriores, como mostra a Figura 6.

De acordo com o Instituto de Gestão de Águas do Rio Grande do Norte (IGARN, 2017), o volume que pode ser armazenado na Barragem de Pau 


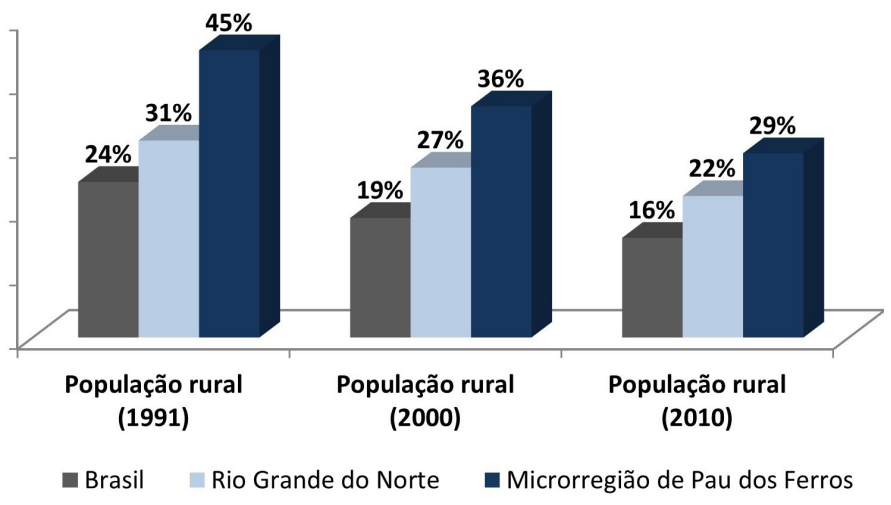

Fig. 5. Comparativo da População Rural (\%) 1990-2010 (adaptado de IBGE, 1991, 2000, 2010).

dos Ferros é $54.846 .000,00 \mathrm{~m}^{3}$, e o seu volume morto é $1.092 .710,00 \mathrm{~m}^{3}$.

Assim, por meio da Figura 6, constata-se que em 2011 o volume da Barragem de Pau dos Ferros passou a decrescer e atingiu o volume morto em dezembro de 2014, condição que permaneceu até abril de 2018, quando houve uma recuperação de acumulação. O estado de volume morto voltou em março de 2019, sendo superado apenas em março de 2020. Em 2016, ano foco deste estudo, a quantidade de água armazenada era nula, o que representa uma situação de extrema criticidade. A Figura 7 mostra a situação da Barragem de Pau dos Ferros em 2016.

Apurou-se que a construção da Barragem Pau dos Ferros foi concluída pelo DNOCS em 1967 (ANA, 2017). Apesar do transcurso de 53 anos, não foram identificadas obras de manutenção, como desassoreamento, recuperação de mata no entorno e de ampliação de capacidade. Destacase que, além da sedimentação de material durante todo este tempo, que reduz o volume de armazenamento, a população de Pau dos Ferros/ $\mathrm{RN}$, em 1967, residente na zona urbana era bem menor do que a observada atualmente.

Dessa forma, para atender às necessidades básicas da população pauferrense, foram adotadas medidas emergenciais, como perfuração de poços artesianos e a implantação de uma adutora de engate rápido.

DadoscoletadosnaSecretariade Desenvolvimento Rural de Pau dos Ferros/RN (2016) mostram que a perfuração de poços teve intensificação a partir de 2013 com o objetivo de complementar o abastecimento da adutora de engate rápido. A Figura 8 retrata as caixas d'água associadas à poços perfurados em praças públicas do município de Pau dos Ferros/RN, em que o acesso poderia ser feito por todos os indivíduos.

Embora as condições geofísicas (solo cristalino e água com alto teor de salinidade) do RN não favoreçam a utilização, em larga escala, da

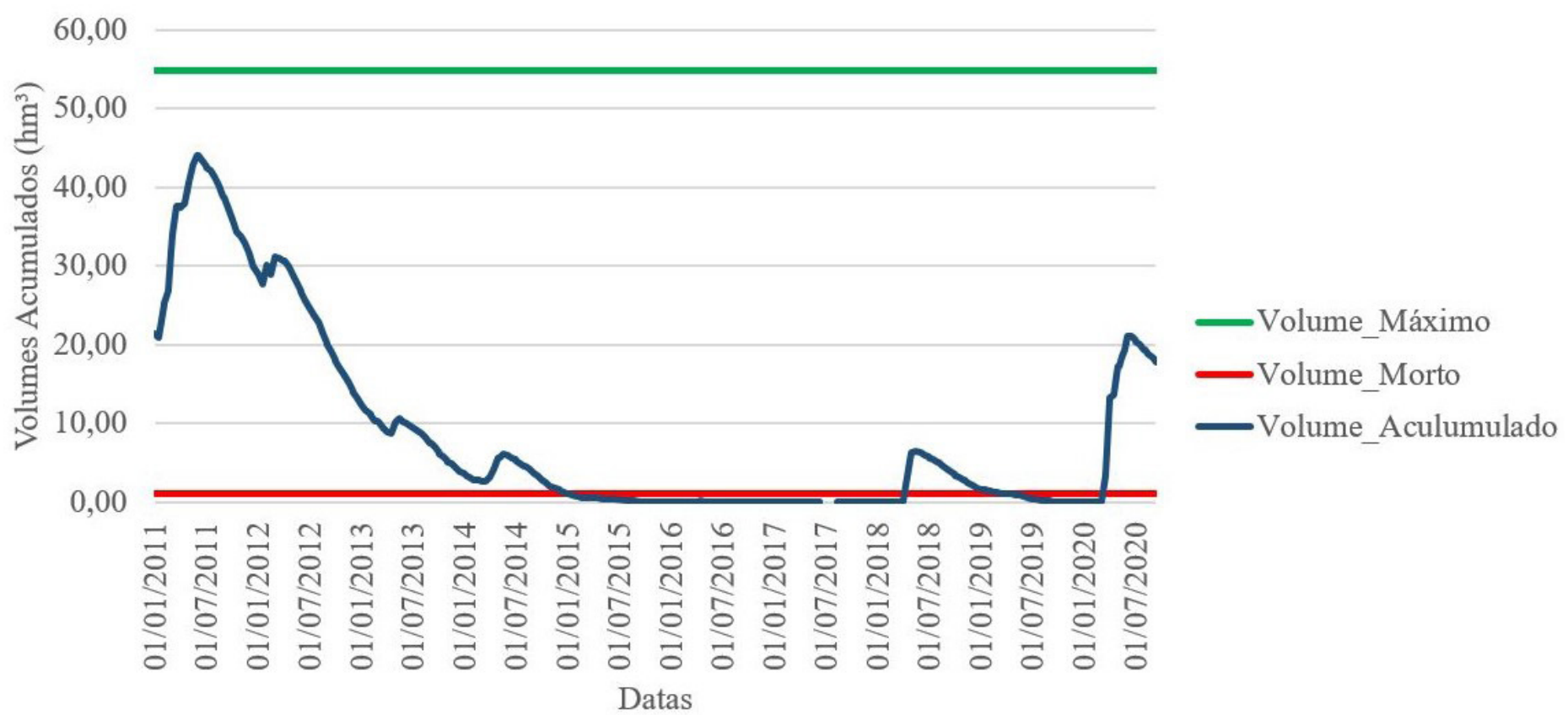

Fig. 6. Evolução Volumétrica da Barragem de Pau dos Ferros (adaptado de ANA, 2020a). 


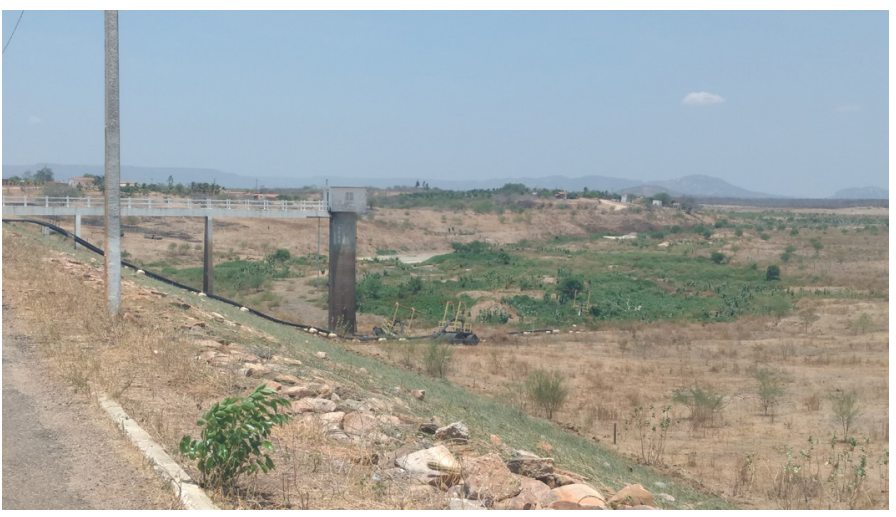

Fig. 7. Barragem de Pau dos Ferros/RN em novembro de 2016.

perfuração de poços, observa-se que as gestões municipais recorreram bastante ao expediente, em alguns casos, provavelmente, para se resguardar de críticas mais acentuadas por parte da opinião pública.

A Tabela 1 apresenta o panorama de perfuração de poços públicos no município de Pau dos Ferros, incluindo zona rural e urbana, entre os anos de 2013 e 2015.

Analisando a Tabela 1, identifica-se que em 2015 o número de poços perfurados foi aproximadamente o dobro da quantidade de 2013. No entanto, há muitos poços secos ou que não foram instalados devido à baixa vazão. Verificou-se que, para poços particulares, não existe um controle.

Enfatiza-se que a estratégia de perfuração de poços por parte do Poder Público não era muito usual, especialmente nos municípios da Microrregião de Pau dos Ferros, em função da incompatibilidade geológica e dos altos custos envolvidos, o que foi modificado a partir de 2011. Basta mencionar que no quadriênio de 2011 a 2014, a Secretaria do Meio Ambiente e dos Recursos Hídricos do Rio Grande do Norte (SEMARH) instalou 223 poços em todo o estado e indicou a realização de locações de 420 poços no ano de 2015, sendo 250 no Alto Oeste

Tabela 1. Quantidade de poços perfurados e situação entre os anos de 2013 e 2015 (Adaptada de Secretaria de

Desenvolvimento Rural de Pau dos Ferros, 2016).

\begin{tabular}{ccc}
\hline Ano & Quantidade & Situação \\
\hline 2013 & 20 & 12 instalados; 7 secos; 1 não \\
instalado \\
2014 & 3 & 2 instalados \\
2015 & 39 & $\begin{array}{c}6 \text { instalados; } 24 \text { secos; } 9 \text { não } \\
\text { instalados }\end{array}$ \\
\hline
\end{tabular}
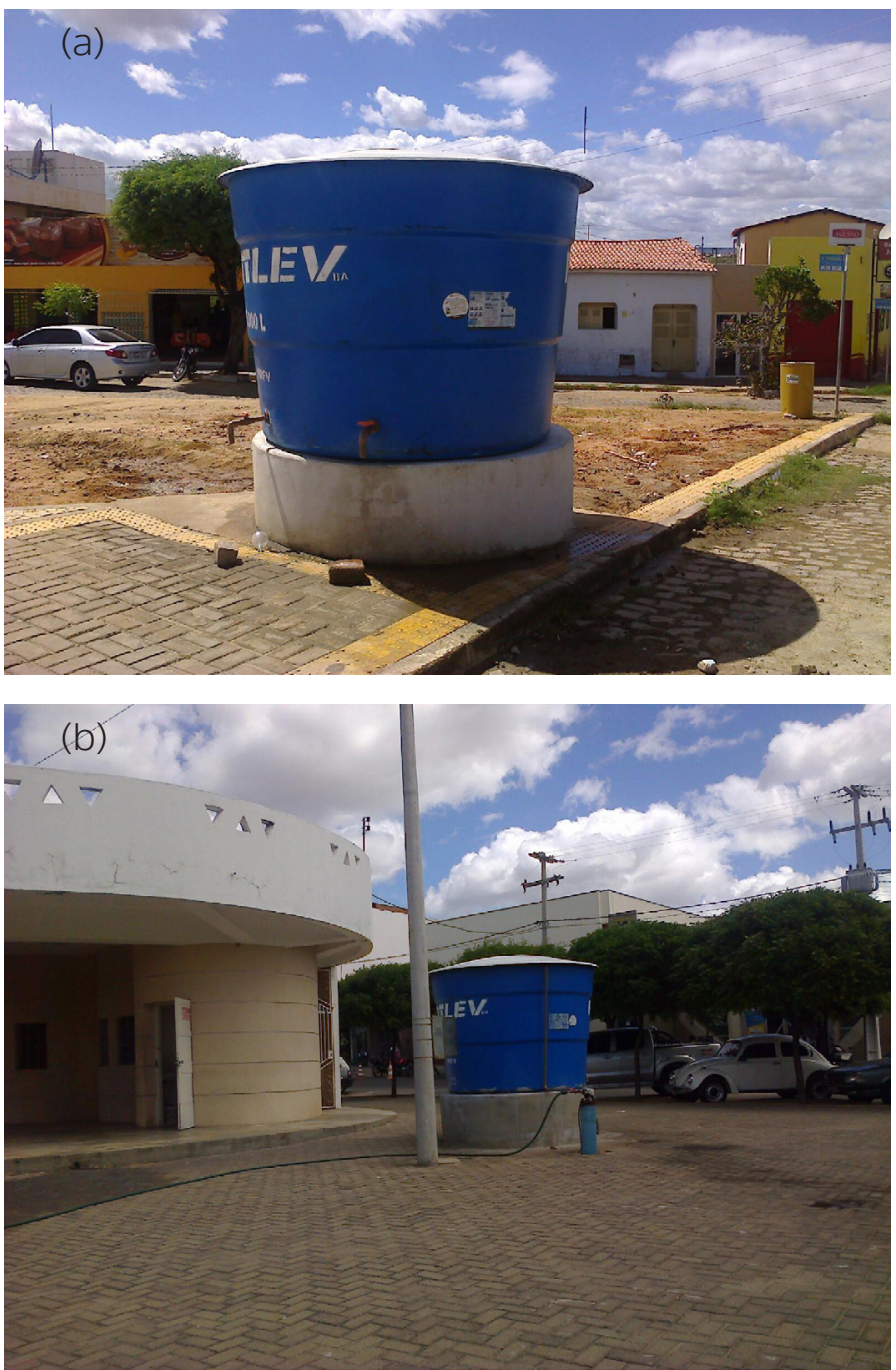

Fig. 8. Caixas d'água de polímero na Praça da Matriz (a) e Praça São Benedito (b) - Pau dos Ferros/RN.

Potiguar, dos quais, cerca de 16\% foram perfurados em Pau dos Ferros/RN (SEMARH, 2015).

A implantação de sistemas adutores completa o rol das ações mais representativas executadas pelo Estado em relação a seca de 2012 a 2017 na Microrregião de Pau dos Ferros. Para o caso de Pau dos Ferros/RN foi instalada uma Adutora Emergencial de Engate Rápido, por meio de uma derivação da Adutora Alto Oeste, que captava água de Santa Cruz (SEMARH, 2016).

Os testes da Adutora Emergencial de Engate Rápido aconteceram em setembro de 2014 e seu funcionamento foi iniciado em outubro deste mesmo ano (IGARN, 2014), por meio do sistema de rodízio, no qual os bairros de Pau dos Ferros/ RN eram divididos em três setores (IGARN, 2015).

A Figura 9 expõe a Adutora Emergencial de Engate Rápido que abastecia Pau dos Ferros/RN 


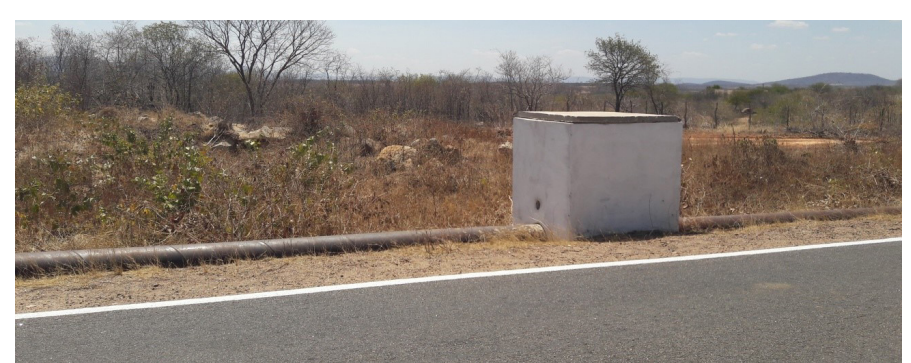

Fig. 9. Adutora emergencial de engate rápido Santa Cruz/RN - Pau dos Ferros/RN.

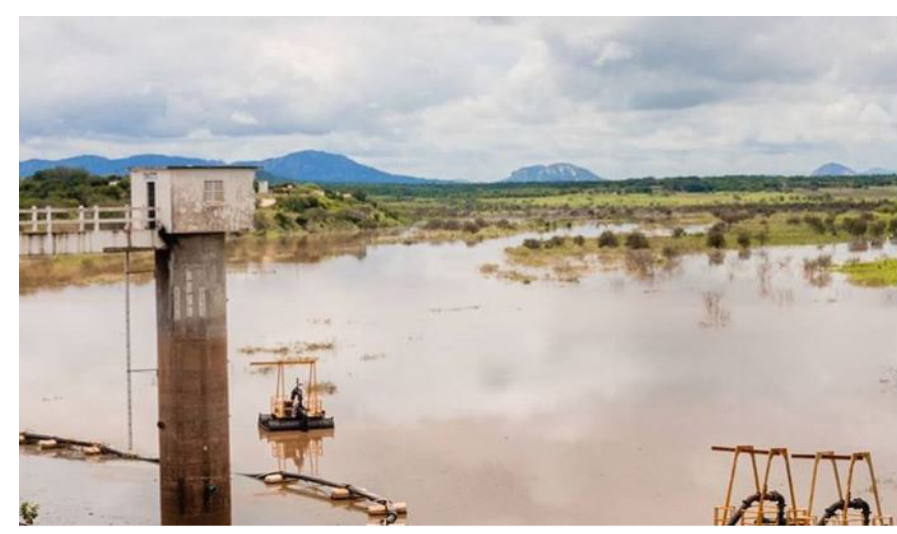

Fig. 10. Barragem de Pau dos Ferros/RN em março de 2020 (IGARN, 2020).

até o ano de 2020. Após aproximadamente 4 anos, a Barragem de Pau dos Ferros voltou a abastecer a cidade em abril de 2020 (IGARN, 2020), em função de seu volume armazenado (Figura 10).

O volume acumulado em 2020 é considerável, se comparado ao de 2016, mas necessita de uma boa gestão de recursos hídricos para que possa atender aos usos previstos com efetividade e em um período de tempo planejado, uma vez que ações paliativas, como é o caso de Adutora Emergencial de Engate Rápido e perfuração de poços, embora contribuam muito para o acesso à água, não se configuram como promotoras da segurança hídrica a longo prazo. Dessa forma, se faz necessário, dentre outras medidas: estabelecer regras de usos para o reservatório principal, regularizar usuários, executar um bom gerenciamento da distribuição hídrica, reduzir o número de perdas, conscientizar a população para uso racional.

\section{Considerações finais}

Por meio dos dados analisados, diagnosticouse a perda da representatividade demográfica e econômica das áreas rurais na composição estrutural dos municípios analisados frente ao aumento da importância das áreas urbanas. $\mathrm{O}$ que se observou em termos gerais nos municípios que compõem a microrregião analisada no período analisado foram: i) redução da população rural e; ii) redução da participação do PIB agropecuário em relação ao PIB Total Municipal. A queda do setor agropecuário apresentado na região estudada não pode ser atribuída apenas ao fator climático, pois este é um fenômeno natural que ocorre de forma periódica na região, ocasionando longos períodos de estiagem. Grande parte dessas mudanças estruturais na região implicam a falta de um planejamento urbano-regional atrelado a políticas públicas que propiciem o desenvolvimento social e o crescimento econômico da região fundamentados na convivência com o fator clima.

Percebe-se que as medidas de combate à seca, propostas pela solução hídrica resultante de diversas ações governamentais, contribuíram para redução da problemática água, mas, não apresentaram resultados efetivos. Para atender demandas de maneira parcial, foram adotadas medidas emergenciais, como as verificadas no município de Pau dos Ferros/RN: adutora emergencial de engate rápido e perfuração de poços artesianos.

Logo, a gestão eficaz e eficiente dos recursos hídricos e a celeridade na implantação de projetos que venham a colaborar para a redução dos impactos ocasionados pelo déficit hídrico, concomitante com políticas públicas nacionais que se efetivem na região, fazem-se necessárias.

\section{Referências bibliográficas}

$A B$ 'SABER, A. Os domínios de natureza no Brasil: potencialidades paisagísticas. São Paulo: Ateliê Editorial, 2003.

AGÊNCIA NACIONAL DE ÁGUAS (ANA). Reservatórios do semiárido brasileiro: hidrologia, balanço hídrico e operação. Brasília: ANA, 2017.

AGÊNCIA NACIONAL DE ÁGUAS (ANA). Sistema de Acompanhamento de Reservatórios (SAR). Dados Históricos de 2011 a 2020. Brasília: ANA, 2020a. 
AGÊNCIA NACIONAL DE ÁGUAS (ANA). Monitor de Secas. Brasília: ANA, 2020b.

ALBUQUERQUE JÚNIOR, Durval Muniz de. As imagens retirantes. A constituição da figurabilidade da seca pela literatura do final do século XIX e do início do século XX. Varia Historia, v. 33, n. 61, p. 225-251, 2017.

ARTICULAÇÃO NO SEMIÁRIDO BRASILEIRO (ASA). Programa Um Milhão de Cisternas. Disponível em: 〈http://www.asabrasil.org.br/acoes/p1mc>. Acessado em: 10 set. 2020.

ATLAS DO DESENVOLVIMENTO HUMANO NO BRASIL. Atlas do IDHM. Disponível em: <http:// www.atlasbrasil.org.br/2013/pt/consulta/>. Acesso em: 28 de outubro de 2016.

BLECHER, B. A tecnologia que domou os desertos. Disponivel em: <http://revistagloborural.globo. com/Revista/Common/O,EMI292798-18281,00-A+ TECNOLOGIA+QUE+DOMOU+OS+DESERTOS.html>. Acessado em: 10 de novembro de 2016.

BRASIL. Decreto $\mathrm{n}^{\circ} \mathbf{1 . 9 4 6}$, de 28 de junho de 1996. Cria o Programa Nacional de Fortalecimento da Agricultura Familiar - PRONAF, e dá outras providências. Disponível: <http://www.planalto.gov. br/ccivil_03/decreto/D1946.htm>. Acesso em: 15 set. 2020.

BRASIL. Lei $\mathbf{n}^{\circ} \mathbf{1 0 . 6 9 6}$, de 2 de julho de 2003. Dispõe sobre a repactuação e o alongamento de dívidas oriundas de operações de crédito rural, e dá outras providências. Disponível: <http://www. planalto.gov.br/ccivil_03/LEIS/2003/L10.696.htm>. Acesso em: 15 set. 2020.

DANTAS, J. R. Q. As cidades médias no desenvolvimento regional: um estudo sobre Pau dos Ferros (RN). Tese (Doutorado em Ciências Sociais) Programa de Pós-Graduação em Ciências Sociais, Universidade Federal do Rio Grande do Norte, 2014.

DANTAS, J. R. Q.; CLEMENTINO, M. L. M.; FRANÇA,
R. S. A Cidade Média Interiorizada: Pau Dos Ferros no Desenvolvimento Regional. In: XII Seminário Internacional RII, 2014, Salvador. Anais do XIII Seminário Internacional RII. Salvador: SEl/Bahia, 2014. v. único. p. 1-21.

DANTAS, J. R. Q.; FRANÇA, R. S. Desenvolvimento humano e hierarquia urbana: um estudo do IDHM nos municípios Potiguares. Trabalho apresentado no GT 4 Dinâmicas Socioeconômicas no Território III Seminário de Desenvolvimento Regional, Estado e Sociedade - SEDRES, Blumenau (SC), ocorrido entre 14 e 16 de setembro de 2016.

GRUPO DE TRABALHO PARA DESENVOLVIMENTO DO NORDESTE (GTDN). Uma política de desenvolvimento econômico para o Nordeste. Recife/PE SUDENE, 1959. Disponível em: <https:// web.bndes.gov.br/bib/jspui/handle/1408/17760>. Acesso em: 17 set. 2020.

IBGE - Instituto Brasileiro de Geografia e Estatística. Censo demográfico 1990. Rio de Janeiro: IBGE, 1991.

IBGE - Instituto Brasileiro de Geografia e Estatística. Censo demográfico 2000. Rio de Janeiro: IBGE, 2000.

IBGE - Instituto Brasileiro de Geografia e Estatística. Censo demográfico 2010. Rio de Janeiro: IBGE, 2010.

IBGE - Instituto Brasileiro de Geografia e Estatística. Mapas regionais. Semiárido brasileiro. 2018. Disponível em: <https:// www.ibge.gov.br/geociencias/cartas-e-mapas/ mapas-regionais/15974-semiarido-brasileiro. html?=\&t=acesso-ao-produto $>$. Acesso em: 17 jun. 2020.

IBGE - Instituto Brasileiro de Geografia e Estatística. Cidades. 2020. Disponível em https://cidades.ibge. gov.br/. Acesso em: 17 jun. 2020.

IBGE - Instituto Brasileiro de Geografia e Estatística. Produto Interno Bruto do Municípios 2002- 
2017. In: IBGE. Sidra: sistema IBGE de recuperação automática. Rio de Janeiro, 2011a. Disponível em: <https://sidra.ibge.gov.br/pesquisa/pib-munic/ tabelas $>$. Acesso em: 10 de jan. 2020.

IGARN, Imagem da Barragem de Pau dos Ferros/ RN, 2020. Disponivel em: <https://www.instagram. com/p/B97nZPOIhx1/>. Acesso em: 17 set. 2020.

INSTITUTO DE GESTÃO DAS ÁGUAS DO RIO GRANDE DO NORTE (IGARN). Adutora de Pau dos Ferros deve entrar em operação nos próximos dias. 2014.

INSTITUTO DE GESTÃO DAS ÁGUAS DO RIO GRANDE DO NORTE (IGARN). Em Pau dos Ferros, Governadora confere funcionamento da adutora de Engate Rápido. 2014.

INSTITUTO DE GESTÃO DAS ÁGUAS DO RIO GRANDE DO NORTE (IGARN). Rodízio em Pau dos Ferros terá alteração em seu cronograma. 2015.

INSTITUTO DE GESTÃO DAS ÁGUAS DO RIO GRANDE DO NORTE (IGARN). Bacia Apodi/Mossoró. 2017.

INSTITUTO DE GESTÃO DAS ÁGUAS DO RIO GRANDE DO NORTE (IGARN). Pau dos Ferros volta a ser abastecida pela barragem. 2020 .

MALVEZZI, R. Semi-Árido: uma visão holística. Brasília: Confea, 2007.

SECRETARIA ESTADUAL DO MEIO AMBIENTE E DOS RECURSOS HÍDRICOS DO RIO GRANDE DO NORTE (SEMARH). Governo do RN anuncia a perfuração de 300 poços artesianos em 2015. 2015. Disponível em: <http://tribunadajustica.com. br/governo-do-rn-anuncia-a-perfuracao-de-300pocos-artesianos-em-2015/>. Acesso em 16 jun. 2020.

SECRETARIA ESTADUAL DO MEIO AMBIENTE E DOS RECURSOS HÍDRICOS DO RIO GRANDE DO NORTE (SEMARH). Pau dos Ferros recebe aumento na oferta de água de mais $\mathbf{3 5}$ mil litros por hora. 2016.
SILVA, R. M. A. Entre dois paradigmas: combate à seca e convivência com o semi-árido. Sociedade e estado, v. 18, n. 1-2, p. 361-385, 2003.

SILVA, R. M. A. Entre o Combate à Seca e a Convivência com o Semi-Árido: políticas públicas e transição paradigmática. Revista Econômica do Nordeste, Fortaleza, v. 38, n. 3, p. 466- 485, jul-set. 2007.

SOUTO, L. V.; SOUSA JUNIOR, A. M.; LIMA JÚNIOR, F. O. Economia e Aspectos da Urbanização na Microrregião de Pau dos Ferros, Rio Grande do Norte, Brasil. Revista Brasileira de Assuntos Regionais e Urbanos, Goiânia, v. 5, n. 2, p. 182-198, jul./dez. 2019.

SUPERINTENDÊNCIA DO DESENVOLVIMENTO DO NORDESTE (SUDENE). Resolução $n^{\circ}$ 115/2017. Aprova a Proposição $n^{\circ}$ 113/2017, que acrescenta municípios a relação aprovada pela Resolução CONDEL n 107, e 27 de julho de 2017. Disponível em: <http://sudene.gov.br/images/arquivos/ conselhodeliberativo/resolucoes/resolucao11523112017-delimitacaodosemiarido.pdf $>$. Acesso em 16 jun. 2020. 